\section{Cognitive behavioural therapy was more effective for panic disorder when given with 6 hours of total therapist contact than with 2 or 0 hours}

\author{
Sharp DM, Power KG, Swanson V. Reducing therapist contact in cognitive behaviour therapy for panic disorder and \\ agoraphobia in primary care: global measures of outcome in a randomised controlled trial. Br J Gen Pract 2000 \\ Dec;50:963-8.
}

QUESTION: In adults with panic disorder with or without agoraphobia, does the amount of therapist contact affect the effectiveness of cognitive behavioural therapy (CBT)?
Source of funding: no external funding.

For correspondence: Dr D M Sharp, University of Hull, Institute of Rehabilitation, School of Medicine, 215 Anlaby Road, Hull HU3 $2 P G$, UK. Fax +44(0)1482675636.

\section{Design}

Randomised \{allocation concealed*\}†, blinded (outcome assessor)*, controlled trial with 12 weeks of follow up.

\section{Setting}

26 general practices in eastern Scotland, UK.

\section{Patients}

104 patients who were 18-70 years of age (mean age 38 y) and had panic disorder with or without agoraphobia according to DSM-III- $R$, a Hamilton Anxiety Scale score $\geqslant 15$, a Montgomery Asberg Depression Rating Scale $\leqslant 20$, symptoms lasting $\geqslant 3$ months, and no psychological treatment for panic disorder and agoraphobia in the preceding 6 months. $88 \%$ of patients completed the study.

\section{Intervention}

CBT was given with 1 of 3 levels of therapist contact: standard contact $(n=36)$, minimum contact $(n=31)$, or bibliotherapy $(\mathrm{n}=35)$. CBT involved exposure and behavioural and cognitive panic management techniques. All patients received the same treatment manual. Patients in the standard contact group had eight 45 minute sessions over 12 weeks $(6 \mathrm{~h}$ total therapist contact). Patients in the minimum contact group had three 30 minute sessions and three 10 minute sessions ( $2 \mathrm{~h}$ total therapist contact). Patients in the bibliotherapy group had assessments on 3 days (90 min contact for assessment only).

\section{Main outcome measures}

Severity of illness (global symptom severity scale), change in symptoms (clinical global improvement scale), and social functioning (Sheehan Disability Scale).

\section{Main results}

The table shows the results. CBT was most effective in the standard contact group and least effective in the bibliotherapy group.

\section{Conclusion}

In adults with panic disorder (with or without agoraphobia), cognitive behavioural therapy was more effective when given with 6 hours of therapist contact than with 2 hours of therapist contact or bibliotherapy.

*See glossary.

$\dagger$ Information provided by author.
Cognitive behavioural therapy with standard therapist contact (Std), minimum contact (Min), or bibliotherapy (Bib) for panic disorder with or without agoraphobia $\$$

\begin{tabular}{|c|c|c|c|}
\hline Outcomes at 12 weeks & Comparisons & $\begin{array}{l}\text { Unadjusted } \\
\text { means }\end{array}$ & $\begin{array}{l}\text { Mean difference } \\
(95 \% \mathrm{CI})\end{array}$ \\
\hline \multirow{2}{*}{$\begin{array}{l}\text { Global symptom severity (low score= } \\
\text { less severity) }\end{array}$} & Std $v$ Min & $2.2 v 3.1$ & $0.9(0.2$ to 1.6$)$ \\
\hline & Std $v$ Bib & $2.2 v 3.6$ & $1.4(0.7$ to 2.1$)$ \\
\hline $\begin{array}{l}\text { Psychologist rated CGI (low score= } \\
\text { better improvement) }\end{array}$ & Std $v$ Bib & $1.8 v 3.3$ & 1.5 (0.8 to 2.2$)$ \\
\hline \multirow{2}{*}{$\begin{array}{l}\text { Sheehan Disability Scale (SDS)—work } \\
\text { (high score=more disruptions) }\end{array}$} & Std $v$ Bib & $2.2 \vee 4.4$ & 2.2 (0.7 to 3.7$)$ \\
\hline & Std $v$ Min & $2.2 v 4.1$ & $1.9(0.4$ to 3.4$)$ \\
\hline \multirow{2}{*}{$\begin{array}{l}\text { SDS—social life (high score=more } \\
\text { disruptions) }\end{array}$} & Std $v$ Bib & $2.1 v 4.3$ & $2.2(0.6$ to 3.8$)$ \\
\hline & Min $v$ Bib & $3.3 v 4.3$ & $1.0(-0.7$ to 2.7$)$ \\
\hline \multirow{2}{*}{$\begin{array}{l}\text { SDS-home life (high score=more } \\
\text { disruptions) }\end{array}$} & Std $v$ Bib & $2.1 v 4.4$ & 2.3 (0.8 to 3.9$)$ \\
\hline & Min $v$ Bib & $2.9 \vee 4.4$ & $1.5(-0.2$ to 3.1$)$ \\
\hline
\end{tabular}

$\mp C G \mathrm{l}=$ clinical global improvement. Mean differences and $\mathrm{Cl}$ calculated from data in article.

\section{COMMENTARY}

This timely study by Sharp et al yields good news and bad news. The bad news is that when panickers were treated with CBT, benefits of treatment decreased when therapist contact decreased. The study, however, also yields 3 pieces of good news.

Firstly, patients who received the most therapist contact did well, and the 6 hours of contact they received is less than that provided in many other studies of CBT. ${ }^{1}$

Secondly, patients who received less therapist contact did get some benefit. This result suggests the potential for a stepped care approach to treatment, in which panickers might first receive a low intensity intervention and those who do not respond are offered higher levels of care.

Thirdly, the study shows the feasibility of adapting treatments that are effective in a specialty setting to a primary care setting. This is important because most panickers seek treatment from their primary care physician. The medical setting is convenient and can capitalise on patients' already established trust in their physicians. Physicians can also support the panicker's participation in treatment. Of course, a controlled study that randomly assigns patients to treatment in primary care and specialty settings is needed to definitively evaluate the benefits of treating panickers in a primary care setting.

Finally, we offer a methodological point. We recommend that investigators conducting a study of this sort report the percentage of patients reaching a clinically meaningful criterion outcome. ${ }^{2}$ In the case of panickers, an obvious criterion is whether they are panic free. ${ }^{1}$ Reporting outcome in this way would provide information about the clinical significance of treatment benefits, facilitate comparison of results across studies, and promote stepped care approaches to treatment.

Jacqueline B Persons, PhD University of California at Berkeley and San Francisco Bay Area Center for Cognitive Therapy Kristen L Valus, PsyD San Francisco Bay Area Center for Cognitive Therapy Oakland, California, USA

1 Barlow DH, Craske MG, Cerny JA, et al. Behavioral treatment of panic disorder. Behavion Therapy 1989;20:261-82.

2 Jacobson NS, Truax P. Clinical significance: a statistical approach to defining meaningful change in psychotherapy research.J Consult Clin Psychol 1991;59:12-9. 